\title{
EFEITOS DA CORREÇÃO DA ACIDOSE METABÓLICA COM BICARBONATO DE SÓDIO SOBRE O CATABOLISMO PROTÉICO NA INSUFICIÊNCIA RENAL CRÔNICA
}

\section{THE EFFECTS OF THE CORRECTION OF METABOLIC ACIDOSIS WITH SODIUM BICARBONATE ON PROTEIN CATABOLISM IN CHRONIC KIDNEY FAILURE}

\author{
Denise MAFRA ${ }^{1}$ \\ Roberto Carlos BURINI²
}

RESUMO

\begin{abstract}
A desnutrição protéico-energética constitui problema comum aos pacientes com insuficiência renal crônica, influenciando diretamente na sua morbi-mortalidade. A acidose metabólica tem papel no catabolismo protéico, ativando a via proteolítica proteasoma-ubiquitina, dependente de adenosina trifosfato, e conjuntamente com glicocorticóides induz uma maior atividade na desidrogenase que degrada os aminoácidos de cadeia ramificada. Esta revisão teve como objetivo descrever o mecanismo pelo qual a acidose metabólica nos pacientes com insuficiência renal crônica promove o catabolismo protéico, favorecendo assim a desnutrição, bem como avaliar os efeitos do uso de bicarbonato de sódio na correção da acidose e conseqüentemente redução do catabolismo protéico. Pesquisas mostram melhora da acidose pelo uso de bicarbonato de sódio e conseqüente redução do catabolismo protéico na insuficiência renal crônica, podendo ser esta uma conduta promissora na atenuação da desnutrição nestes pacientes.
\end{abstract}

Termos de indexação: insuficiência renal crônica, catabolismo protéico, acidose, bicarbonato de sódio, desnutrição protéico-energética.

\section{ABSTRACT}

Protein-Energy Malnutrition is common among patients with chronic kidney failure, thus increasing morbidity and mortality. Several studies have shown that metabolic acidosis is a major cause of muscle protein breakdown, and recently it was attributed to ATP-dependent ubiquitin-proteasome proteolytic pathway. Acidosis, plus glucocorticoids, also respond to increasing branched-chain amino acids oxidation. In this review, the impact of metabolic acidosis on protein and amino acid metabolism is examined in order to understand its effect on lean body mass and the nutritional status of patients with chronic kidney failure. The study also observes whether or not sodium bicarbonate supplementation is beneficial to chronic kidney failure patients. In summary, there is a preliminary evidence suggesting that the correction of acidosis using sodium bicarbonate reduces protein degradation in chronic kidney failure patients, thus emerging as a potential therapy for reducing protein-energy malnutrition among them.

Index terms: kidney failure chronic, protein catabolism, acidosis, sodium bicarbonate, protein-energy mulnutrition.

\footnotetext{
${ }^{(1)}$ Departamento de Alimentos e Nutrição Experimental, Faculdade de Ciências Farmacêuticas, Universidade de São Paulo. Av. Lineu Prestes, 580, Bloco 14, Butantã, 05508-030, Capital, SP, Brasil. Correspondência para/Correspondece to: D. MAFRA. E-mail: dm@usp.br

${ }^{(2)}$ Departamento de Clínica Médica, Faculdade de Medicina, Universidade Estadual Paulista.
} 


\section{INTRODUÇÃO}

A Insuficiência Renal Crônica (IRC) consiste na perda progressiva e irreversível da função renal (glomerular, tubular e endócrina), de tal forma que em suas fases mais avançadas, os rins não conseguem mais manter a normalidade do meio interno do paciente (Júnior Romão, 1994). Nestas condições, os pacientes apresentam comprometimento do seu estado nutricional, em decorrência não só da constante inapetência, como também pelos distúrbios metabólicos gerados pela IRC e suas intercorrências como: infecções, sangramentos, expoliações hidroeletrolíticas e iatrogenia. Na falência renal há elevada excreção de bicarbonato, devido à diminuição na reabsorção do bicarbonato, o que poderia causar a caquexia (Narins et al., 1987).

A caquexia é um grande problema da IRC e que influencia diretamente a morbi-mortalidade dos pacientes renais, com perda progressiva da massa corporal magra e distúrbios no metabolismo de aminoácidos (Bailey \& Mitch, 1996; Reaich et al., 1996; Garibotto, 1999). Acresce-se que também a acidose metabólica aumenta a degradação protéica resultando em perda muscular e balanço nitrogenado negativo. Sabe-se que o catabolismo de aminoácidos ramificados (AACR) está aumentado na acidose, associado à IRC, e que a via proteolítica ubiquitina- proteasoma dependente de Adenosina Trifosfato (ATP) parece estar envolvida na degradação protéica decorrente da acidose (Bailey et al., 1996).

Esta revisão objetivou descrever o mecanismo pelo qual a acidose metabólica nos pacientes com IRC promove o catabolismo protéico, favorecendo assim a desnutrição, bem como, avaliar os efeitos do uso de bicarbonato de sódio na correção da acidose e conseqüentemente redução do catabolismo protéico.

\section{Acidose e catabolismo protéico}

Existem vários fatores que levam ao hipercatabolismo protéico na IRC como o baixo consumo energético; alterações endócrinas (resistência à insulina e hiperglucagonemia, resistência ao hormônio do crescimento e ao IGF-I e hiperparatireoidismo), insuficiência cardíaca e anemia, infecções e inflamações, terapia com glicocorticóides e a acidose metabólica (Bergstrom et al., 1990). Porém, a acidose metabólica parece ser a principal causa do elevado catabolismo protéico destes pacientes (Greiber \& Mitch, 1992; Carr et al., 1994; Laville \& Fouque, 1995; Price et al., 1996; Ahmed \& Kopple, 1997; Bailey, 1998; Lim et al., 1998; Mitch, 1998).

Com relação às mudanças no pH muscular, decorrentes da acidose, Bailey et al. (1996) avaliaram a influência da infusão de $\mathrm{HCl}$ no pH intracelular em curto e longo período de tempo usando ${ }^{13} \mathrm{P}-\mathrm{NMR}$ (Ressonância
Magnética Nuclear). Observaram que a acidose aguda não altera o $\mathrm{pH}$ intracelular, porém a crônica reduz o $\mathrm{pH}$, sugerindo que a capacidade tampão intracelular é reduzida com o tempo. É importante ressaltar, que a baixa concentração de bicarbonato sérico não diagnostica acidemia, medidas diretas do pH sangüíneo promovem informação mais segura sobre a existência de acidose (Ahmed \& Kopple, 1997).

\section{Efeito da acidose sobre o metabolismo de proteínas e aminoácidos}

A acidose é uma complicação da IRC bem conhecida (Bailey \& Mitch, 1996; Reaich et al., 1996). Sabe-se, também, que o grau de falência renal está relacionado com a perda de massa magra, havendo relação linear positiva entre a concentração de creatinina plasmática e os níveis de degradação protéica (Biolo et al., 1998). Desta forma, o metabolismo protéico está alterado na IRC, com balanço nitrogenado negativo, perda de massa magra e níveis plasmáticos reduzidos de aminoácidos essenciais (AAE). Quando a proteína da dieta é reduzida a $0,6 \mathrm{~g} / \mathrm{kg} / \mathrm{dia}$, há intensa redução na oxidação de $\mathrm{AAE}$, resultando em melhor utilização da proteína da dieta. Porém, mesmo assim, em função da uremia, a perda protéica pode persistir (Mitch, 1996).

Uma técnica vem permitindo estimar a taxa de síntese e degradação protéica que mostra a diferença arteriovenosa para fenilalanina através do antebraço pelo uso de ${ }^{3} \mathrm{H}$-fenilalanina (Phe). Este aminoácido não é metabolizado no músculo, assim a taxa de Phe liberada através do antebraço reflete a taxa de incorporação em proteínas e a taxa de Phe no sangue venoso reflete a liberação pela degradação muscular (Garibotto et al., 1996).

O turnover protéico foi estudado pela infusão de ${ }^{3} \mathrm{H}$-Phe (L-[2,6-3H] Phenylalanine), em 13 pacientes renais, no estado pós-absortivo, sendo nove acidóticos $\left(\mathrm{HCO}_{3}{ }^{-}=20 \pm 0,5 \mathrm{mEq} / \mathrm{L}\right)$ e quatro com balanço ácido-básico normal $\left(\mathrm{HCO}_{3}^{-}=25 \pm 0,3 \mathrm{mEq} / \mathrm{L}\right)$. Os níveis de fenilalanina foram maiores nos pacientes acidóticos, sugerindo que a acidose metabólica pode aumentar os níveis de degradação protéica muscular nestes pacientes (Garibotto et al., 1996).

Mudanças nas concentrações de aminoácidos e proteínas musculares foram estudadas em 4 pacientes renais crônicos acidóticos (bicarbonato arterial: 19,2 mmol/L) e em 5 indivíduos saudáveis. Pela infusão de ${ }^{3} \mathrm{H}$-Phe verificou-se um aumento da degradação protéica associado à acidose metabólica, e que era inversamente proporcional à concentração de bicarbonato arterial (Garibotto et al., 1992).

A leucina marcada no primeiro carbono tem sido também utilizada para estudar o metabolismo protéico, pois na sua oxidação há liberação do isótopo como $\mathrm{CO}_{2}$, 
que pode ser medido no ar expirado (Bailey, 1998; Newby \& Price, 1998). Assim, May et al. (1992), examinaram o impacto da acidose crônica no turnover de aminoácidos corporal e sua oxidação em ratos com infusão de $\mathrm{L}\left[1-{ }^{14} \mathrm{C}\right]$ Leucina com a finalidade de observar a produção de ${ }^{14} \mathrm{CO}_{2}$. Verificaram maior oxidação da leucina na IRC, O que sugere alterações no metabolismo dos aminoácidos de cadeia ramificada (AACR).

Os AACR são transportados para as células pelo sistema L-transportador, no espaço intracelular são transaminados, reversivelmente, à cetoácidos de cadeia ramificada (CACR) pelas aminotransferases, com o $\alpha$-cetoglutarato e glutamato servindo de aceptor ou doador de $\mathrm{NH}_{2}$, respectivamente. O cetoácido de cadeia ramificada é descarboxilado irreversivelmente pela desidrogenase $\alpha$-cetoácido de cadeia ramificada (BCKAD) e oxidado (Laville \& Fouque, 1995; England et al., 1996) (Figura 1). England et al. (1995) observaram que a indução de acidose em ratos provocou aumento da atividade da BCKAD no músculo esquelético, com o RNAm desta enzima apresentando valores 10 vezes maiores.

Estudando os efeitos da acidose no metabolismo de aminoácidos e proteínas, Bergström et al. (1990), encontraram correlação linear entre os níveis de bicarbonato, em pacientes pré-dialisados, e valina livre no músculo sugerindo que a acidose pode levar a maior proteólise e depleção de aminoácidos. Pacientes com IRC e acidose têm níveis reduzidos de AACR, especialmente de valina (Bailey, 1998). Carr et al. (1994) avaliaram o perfil de aminoácidos plasmáticos em 7 indivíduos-controles e em 7 idosos com IRC e observaram que os pacientes urêmicos tiveram menores níveis plasmáticos não só de valina, mas também de tirosina, fenilalanina e triptofano e altas concentrações de histidina quando comparados com o grupo controle, e que isto foi relatado em estágios moderados da doença.

Em estudo realizado com ratos acidóticos, Cupisti et al. (1993), demonstraram que a acidose induz mudanças no perfil de aminoácidos, incluindo aumento nos níveis de treonina, histidina, prolina, serina e glicina e diminuição nos níveis de triptofano. Essas mudanças são similares às achadas nos pacientes urêmicos, sugerindo papel patogênico da acidose na piora do metabolismo da proteína endógena.

A resposta precoce à acidose metabólica se dá pelo aumento na degradação da proteína muscular provendo o nitrogênio necessário para aumentar a produção de glutamina, principal carregador de $\mathrm{H}^{+}$, até os rins, onde origina amônia e $\mathrm{H}^{+}$, excretados na urina (Figura 1). Pacientes com IRC são incapazes de manter o balanço ácido-básico e por isso há perda contínua de proteínas musculares para formar glutamina (Mitch et al., 1994).

\section{Mecanismos proteolíticos}

Existem algumas hipóteses sobre os mecanismos que podem estar envolvidos na ação da acidose sobre o catabolismo protéico (Laville \& Fouque, 1995; Bailey, 1998):

- Estimulação da transcrição dos genes que codificam enzimas proteolíticas;

- Ativação dos sistemas cálcio dependentes;

- Alteração nos níveis de corticosteróides e na atividade do hormônio de crescimento;

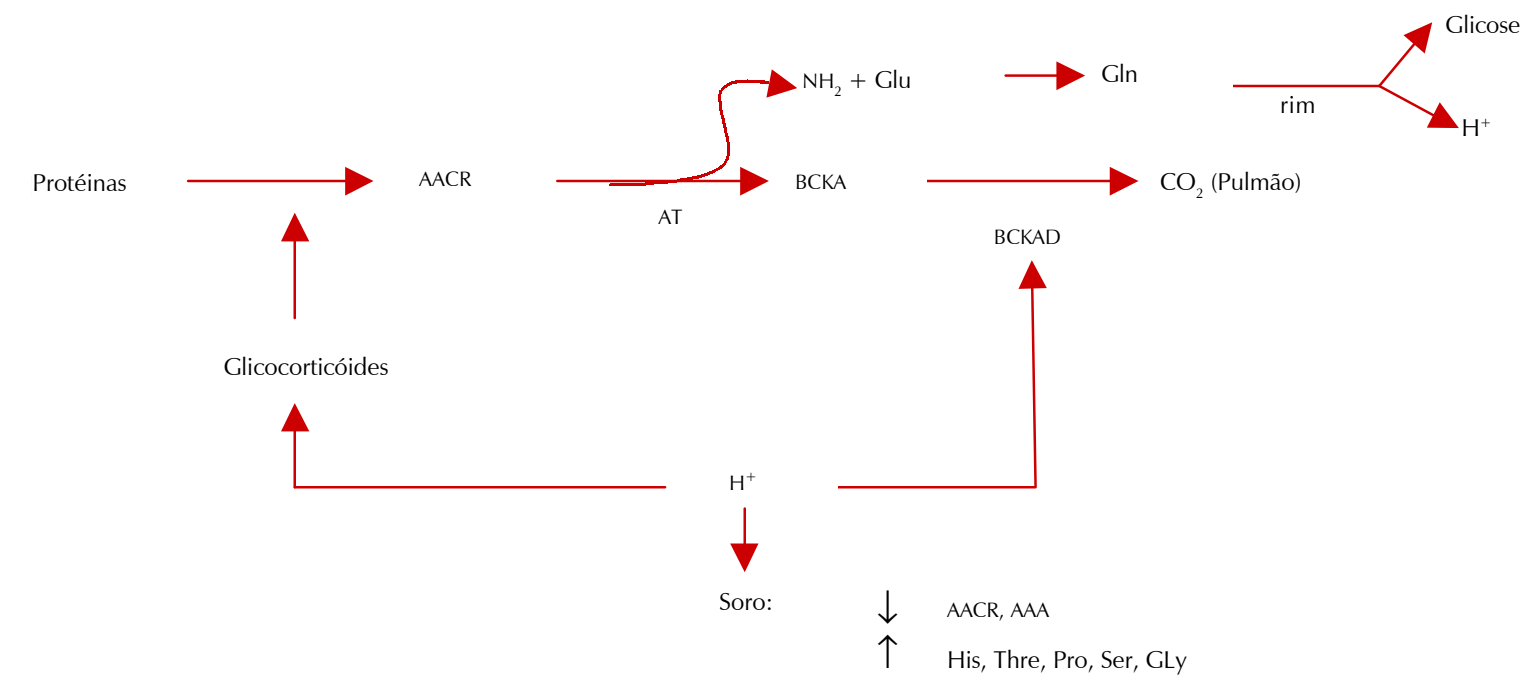

AACR: aminoácidos cadeia ramificada; AT: amino transferases, BCKA: cetoácidos dos AACR; BCKAD: BCKA desidrogenase; AAA: aminoácidos Aromáticos

Figura 1. Efeito da acidose sobre o metabolismo de proteínas e aminoácidos. 
- Depleção de ATP que inibe a estimulação do proteossomo e,

- Ativação da protease lisossomal.

A ativação destas enzimas, pela uremia e acidose, no músculo esquelético, podem ser dependentes de glicocorticóides (England et al., 1995).

A acidose metabólica aumenta a proteólise no músculo esquelético na presença de insulina e este efeito é ausente em ratos adrenalectomizados. Como a uremia aumenta os níveis de corticosterona, este hormônio poderia estar contribuindo tanto para o aumento da proteólise, como degradação de AACR (Figura 1) e possível inibição da síntese protéica (Greiber \& Mitch, 1992). Em ratos adrenalectomizados acidóticos, a proteólise aumenta só quando eles são suplementados com concentrações fisiológicas de glicocorticóides, sugerindo que na acidose, os glicocorticóides são necessários para o aumento da proteólise (England \& Price, 1995).

$\mathrm{Na}$ IRC, a via proteolítica ubiquitina-proteasoma, dependente de ATP, é ativada com aumento da transcrição desses genes no músculo. O estímulo para estas respostas incluem acidose e glicocorticóides, mas outras anormalidades endócrinas na IRC como resistência à insulina poderiam contribuir para esta resposta. Em estudo para verificar a influência da insulina, observou-se que este hormônio age como supressor da via ubiquitina- proteosoma, de modo que a resistência à insulina, na uremia, poderia ser outro fator contribuinte para degradação protéica na IRC (Bailey et al., 1997).

\section{Ativação proteolítica na IRC}

As etapas da via de degradação protéica, onde o passo inicial desta, envolve a marcação da proteína a ser destruída. Essa marcação ocorre por conjugação do polipeptídeo com os 76 resíduos de aminoácidos que compõem a molécula de ubiquitina, proteína sintetizada em situação de estresse (Figura 2). O terminal carboxil da glicina, componente da ubiquitina, se liga ao grupo amino do resíduo de lisina do substrato protéico. A seletividade da proteólise está envolvida nesta conjugação. A reação requer ATP, 3 enzimas e para certos polipeptídeos, uma modificação dependente do RNAt (Bailey, 1998).

A proteólise provocada pela via ubiquitina poderia ser a grande responsável pela perda das miofibrilas musculares em roedores (Attaix et al., 1994). Mitch (1996) usando inibidores dos sistemas proteolíticos lisossomal e da proteólise ativada por cálcio, verificaram que mesmo assim, o nível de proteólise continuou aumentado em ratos acidóticos. Entretanto, quando bloquearam a síntese do ATP, observaram inibição da proteólise configurando-se

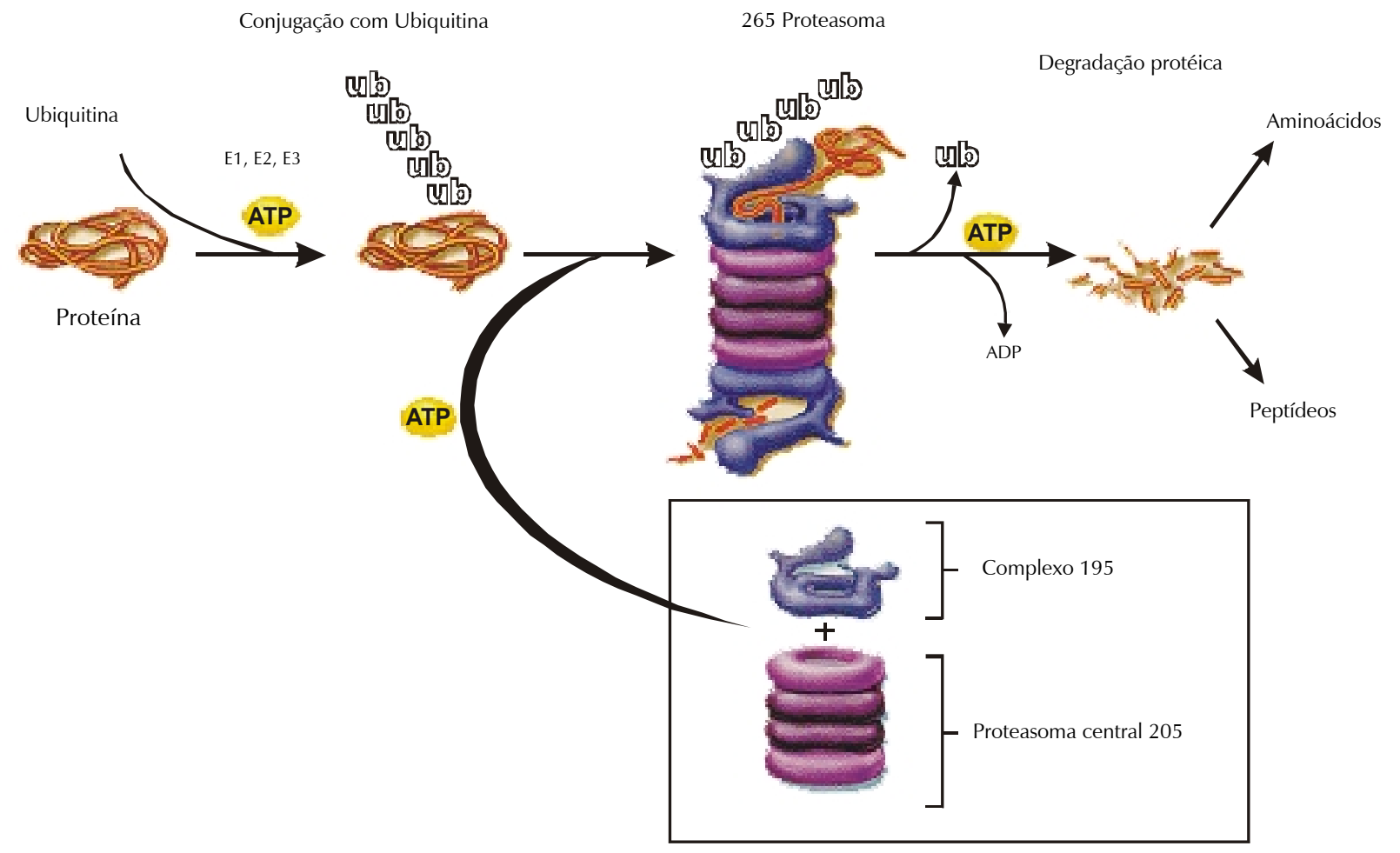

Figura 2. Via proteolítica ubiquitina - proteasomal (adaptado de Mitch \& Goldberg, 1996). 
a responsabilidade do sistema envolvendo ATP-ubiquitina-proteasoma.

A ativação da via dependente de ATP, pela acidose, está associada com o aumento da expressão dos genes que codificam a ubiquitina, subunidades de proteasoma e outras enzimas que participam desta via proteolítica, como o visto pelo aumento do número de RNAm (Bailey, 1998). Sabe-se que os níveis de RNAm do músculo esquelético para o conjugado ubiquitina-enzima $\mathrm{E}_{2}$ aumentam com o jejum e retornam ao normal com a realimentação (Wing \& Banville, 1994).

Os efeitos da acidose metabólica ocorrem diretamente pela redução do $\mathrm{pH}$ intracelular ativando genes que codificam proteínas envolvidas no catabolismo protéico (Bailey, 1998).

Assim, a acidose metabólica acelera a degradação protéica muscular, porém não se sabe se este catabolismo é induzido apenas pela acidose ou se os glicocorticóides são necessários para este processo (Mitch, 1996). Por outro lado, sabe-se que a acidose aumenta a produção de glicocorticóides. Esta resposta é benéfica aos indivíduos sem IRC, pois o aumento de glicocorticóides maximiza a síntese de glutamina que permite a excreção renal de ácidos (Figura 1). Porém, na IRC esta resposta é maléfica, pois a combinação da acidose e aumento de glicocorticóide estimularia vias catabólicas não adaptativas. Assim, quando a proteína da dieta é restringida, a acidose bloqueia a redução adaptativa na oxidação de AAE. Como conseqüência, há perda da massa corporal magra (Mitch et al., 1994).

Price et al. (1996) estudando o papel da acidose e dos glicocorticóides, no aumento de RNAm codificadores das proteínas da via proteolítica ATP-ubiquitina-proteasoma, em ratos adrenalectomizados, observaram que o RNAm tanto da ubiquitina como para subunidades $\mathrm{C}_{2}$ e $\mathrm{C}_{9}$ do proteasoma estavam aumentados, nas fibras brancas musculares, nos ratos que receberam glicocorticóides, ao passo que a acidose ou administração de glicocorticóides sozinhos não aumentaram esses RNA. Assim, os glicocorticóides são necessários, mas não diretamente responsáveis pelo aumento da concentração de RNAm que codifica proteínas que participam dessa via proteolítica.

Pela seqüência recentemente aventada (Mitch, 1998), a acidose da IRC seria o estímulo inicial, com maior secreção de glicocorticóides e estes seriam responsabilizados pelo maior número de RNAm das proteínas da via proteolítica ubiquitina-proteosoma. As proteínas musculares são marcadas para degradação pela ligação covalente com a ubiquitina onde o terminal carboxil desta, é ativado pela enzima $\mathrm{E}_{1}$ que é dependente de ATP e seguidamente é acoplada ao grupo amino da lisina pela enzima $\mathrm{E}_{3}$, sendo esta cadeia repetida e 5 ou mais moléculas de ubiquitinas se ligam à proteína. Esse substrato modificado é reconhecido pelo complexo proteolítico chamado proteosoma 26s, onde a porção 19s faz o reconhecimento da proteína ligada à ubiquitina e a porção 20s promove a proteólise. Com isto, há formação de peptídeos de 6 a 12 aminoácidos que são hidrolisados pelas exopeptidases citosólicas (Figura 2).

\section{Efeitos da suplementação de bicarbonato de sódio na acidose e degradação proteíca}

Richard Bright (1831) foi o primeiro pesquisador a sugerir a terapia com álcali como benéfica para o paciente com IRC; Lyon et al. (1930) mostraram que o tratamento com álcali promovia melhora em vários sintomas da uremia, bem como diminuição nos níveis de uréia sangüínea (Bailey, 1998). Desde então, vários outros trabalhos têm mostrado que a correção da acidose, pela suplementação de bicarbonato de sódio, melhora a degradação protéica (Bailey \& Mitch, 1996; Laville \& Fouque, 1995) (Tabela 1).

Papadoyannakis et al. (1984) observaram em 6 pacientes urêmicos, antes e depois da suplementação com bicarbonato de sódio e cloreto de sódio, que houve diminuição de uréia sangüínea em 36\% e melhora significativa do balanço metabólico nitrogenado e de potássio. Entretanto, não houve melhora com o $\mathrm{NaCl}$, indicando que o efeito do bicarbonato foi resultado da correção da acidose metabólica e não da expansão do volume extracelular.

Williams et al. (1991) estudaram a degradação protéica miofibrilar (através da excreção urinária de 3-metil histidina) de pacientes com IRC acidóticos, fornecendo em 2 semanas dietas normoprotéicas e depois uma dieta com 0,6 g de ptn/kg/dia, junto com suplemento de bicarbonato de sódio $(1 \mathrm{mEq} / \mathrm{kg} / \mathrm{d})$, para correção de acidose. Verificaram que com este último tratamento

Tabela 1. Redução da degradação protéica com a suplementação de bicarbonato de sódio.

\begin{tabular}{lccc}
\hline Autores & Casuística & Dose & Duração (dias) \\
\hline Papadoyannakis et al. (1984) & 6 & $0,7-1,2(\mathrm{mEq} / \mathrm{kg} / \mathrm{d})$ & 9 \\
Williams et al. (1991) & 6 & $1(\mathrm{mEq} / \mathrm{kg} / \mathrm{d})$ & 0,0005 \\
Ruston et al. (1998) & 11 & $1,07(\mathrm{mEq} / \mathrm{kg} / \mathrm{d})$ & $<0,01$ \\
Reaich et al. (1993) & 9 & $1,2 \mathrm{~g} / \mathrm{dia}$ & 180 \\
Kooman et al. (1997) & 6 & $0,5-1,0 \mathrm{~g} / \mathrm{dia}$ & 28 \\
\hline
\end{tabular}


houve uma significante redução na degradação protéica $(p<0,01)$.

Reaich et al. (1993) examinaram o efeito da correção da acidose, em pacientes com IRC, sobre o turnover protéico e a oxidação de aminoácidos. Foram estudados 9 pacientes acidóticos com suplementação de $\mathrm{NaCl}$ e $\mathrm{NaHCO}_{3}$ - em períodos diferentes. Concluíram que a correção da acidose, na IRC, diminuiu a degradação protéica, oxidação de aminoácidos e o balanço nitrogenado negativo, além de diminuir a concentração da uréia plasmática. Este estudo mostrou também que o uso de $\mathrm{NaCl}$ como controle para excluir algum efeito da carga aumentada de sódio, não alterou a cinética da ${ }^{13} \mathrm{C}$-leucina.

Em ratos com uremia grave houve aumento da oxidação da leucina e valina, no músculo, devido à acidose. Quando foi administrado bicarbonato de sódio a oxidação desses aminoácidos, nos músculos, foi restaurada (Mitch, 1996).

Cupisti et al. (1996) avaliaram os efeitos da uremia e a influênica do estado ácido-básico no metabolismo protéico e perfil de aminoácidos em ratos nefrectomizados com ou sem suplementação de $\mathrm{NaHCO}_{3}^{-}$e em ratos - controle recebendo $\mathrm{NaHCO}_{3}$. Observaram nos ratos nefrectomizados elevadas concentrações sangüíneas Phe, Gly, Glu, Pro, Ala, porém que os ratos urêmicos suplementados com $\mathrm{NaHCO}_{3}^{-}$não estavam com elevadas concentrações de treonina como visto no grupo sem suplemento $(p<0,05)$. Sugerindo que há alterações no perfil de aminoácidos no início da IRC e que isto está envolvido com balanço ácido-básico.

Pacientes acidóticos dialisados com ou sem suplementação de bicarbonato foram avaliados quanto ao fluxo de leucina corporal total pela infusão de $\mathrm{L}\left[1-{ }^{13} \mathrm{C}\right]$ leucina. Quando a acidose foi corrigida, observou-se que os pacientes se adaptaram à dieta hipoprotéica pela redução da oxidação do aminoácido e da degradação protéica com a síntese de proteína mantida em níveis normais (Mitch \& Goldberg, 1996).

Em pacientes pré-dialisados, a restrição protéica reduz a sobrecarga ácida. Pacientes com depuração de creatinina $<30 \mathrm{~mL} / \mathrm{min}$ devem receber dieta com $0,6 \mathrm{~g}$ de proteína $/ \mathrm{kg} / \mathrm{dia}$, conseqüentemente fazendo com que a suplementação com bicarbonato de sódio possa ser reduzida, isto é importante especialmente para pacientes submetidos à dietas hipossódicas, evitando sobrecarga de $\mathrm{Na}$. Em muitos casos são prescritas doses de 8 a $16 \mathrm{mEq}$ de bicarbonato de sódio 3 vezes ao dia.

Na ausência de acidose metabólica os pacientes com IRC se adaptam à dietas hipoprotéicas mantendo balanço nitrogenado neutro (Bailey, 1998).

\section{CONCLUSÃO}

Nesta revisão, observou-se que na insuficiência renal crônica, devido à incapacidade dos rins em manter o balanço ácido-básico, ocorre acidose metabólica e que esta acidemia promove ativação da via proteolítica proteossoma ubiquitina dependente de ATP, levando à oxidação de aminoácidos e ao catabolismo protéico, podendo haver repercussões no estado nutricional destes pacientes, sendo que a desnutrição é um fato bem documentado em pacientes hemodialisados.

Alguns trabalhos têm mostrado que a suplementação com bicarbonato de sódio para estes pacientes acidóticos melhora a acidose e conseqüentemente, reduz o catabolismo protéico, atenuando assim a desnutrição nestes pacientes. Sendo portanto uma conduta promissora para o tratamento da acidose metabólica nos pacientes com IRC.

\section{REFERÊNCIAS BIBLIOGRÁFICAS}

AHMED, K.R., KOPPLE, J.D. Nutrition in maintenance hemodialysis patients. In: KOPPLE, J.D., MASSRY, S.G. Nutritional management of renal disease. Baltimore : Williams \& Wilkins, 1997. p.588-589.

ATTAIX, D., TAILLANDIER, D., TEMPARIS, S., LARBAUD, D., AUROUSSEAU, E., COMBARET, L., VOISIN, L. Regulation of ATP-ubiquitin-dependent proteolysis in muscle wasting. Reproduction, Nutrition, Development, Paris, v.34, n.6, p.583-597, 1994.

BAILEY, J.L. Metabolic acidosis and protein catabolism mechanisms and clinical implications. Mineral Electrolyte Metabolism, Basel, v.24, n.1, p.13-19, 1998.

BAILEY, J.L., MITCH, W.E. Metabolic acidosis as a uremic toxin. Seminars of Nephrology, New York, v.16, n.3, p.160-166, 1996.

BAILEY, J.L., ENGLAND, B.K., LONG, R.C., MITCH, W.E. Influence of acid loading, extracellular $\mathrm{pH}$ and uremia on intracellular $\mathrm{pH}$ in muscle. Mineral Eletrolyte Metabolism, Basel, v.22, n.1-3, p.66-68, 1996.

BAILEY, J.L., PRICE, S.R., ENGLAND, B.K., JURKOVITZ, C., WANG, X., DING, X., MITCH, W.E. Signals regulating accelerated muscle protein catabolism in uremia. Mineral Electrolyte Metabolism, Basel, v.23, n.3-6, p.198-200, 1997.

BERGSTROM, J., ALVESTRAND, A., FURST, P. Plasma and muscle-free amino acids in maintenance hemodialysis patients without protein malnutrition. Kidney International, New York, v.38, n.1, p.108-116, 1990.

BIOLO, G., TOIGO, G., CIOCCHI, B., MORENA, G., SITULIN, R., VASILE, A., CARRARO, M., FACCINI, L., GUARNIERI, G. Relationship between whole-body protein turnover and serum creatinine in chronically uremic patients. Mineral Electrolyte Metabolism, Basel, v.24, n.4, p.267-272, 1998.

CARR, S.J., LAYWARD, E., BEVINGTON, A., HATTERSLEY, J., WALLS, J. Plasma amino acid profile in the elderly with increasing uraemia. Nephron, Basel, v.66, n.2, p.228-320, 1994.

CUPISTI, A., BARKER, F., BROWN, J., LOCK, C., BEVINGTON, A., HARRIS, K.P.G., WALLS, J. Effects of acid loading on serum amino acid profiles and muscle composition in normal fed rats. Clinical Science, Colchester, v.85, n.4, p.445-449, 1993. 
CUPISTI, A., BAKER, F., BEVINGTON, A., BROWN, J., LOCK, C., HARRIS, K.P.G., WALLS, J. Amino acid profiles and muscle protein composition in rats with a reduced renal mass in the fed state. Nephron, Basel, v.72, n.1, p.183-188, 1996.

ENGLAND, B.K., GREWAL, M., BAILEY, J.L., PRICE, S.R. Acidosis and glicocorticoids induce branched-chain amino acid catabolism. Mineral Eletrolyte Metabolism, Basel, v.22, n.1-3, p.69-71, 1996.

ENGLAND, B.K., GREIBER, S., MITCH, W.E., BOWERS, B.A., HERRING, W.J., McKEAN, M., EBB, R.G., PRICE, S.R., DANNER, D.J. Rat muscle branched-chain ketoacid dehydrogenase activity and mRNA increase with extracelular acidemia. American Journal of Physiology, Bethesda, v. 268, n.6, p.1395-1400, 1995.

ENGLAND, B.K., PRICE, S.R. Acidosis and glucocorticoids interact to provoke muscle protein and amino acid catabolism. Blood Purification, Basel, v.13, n.3-4, p.147-152, 1995.

GARIBOTTO, G., RUSSO, R., SOFIA, A., SALA, M.R., ROBAUDO, C., MOSCATELLI, P., DEFERRARI, G., TIZIANELLO, A. Muscle protein turnover in chronic renal failure patients with metabolic acidosis or normal aci-basic balance. Mineral Eletrolyte Metabolism, Basel, v.22, n.1-3, p.58-61, 1996.

GARIBOTTO, G., RUSSO, R., SALA, M.R., ANCARANI, P., ROBAUDO, C., SOFIA, A., DEFERRARI, G., TIZIANELLO, A. Muscle protein turnover and amino acid metabolism in patients with chronic renal failure. Mineral Eletrolyte Metabolism, Basel, v.18, n.2-5, p.217-221, 1992.

GARIBOTTO, G. Muscle amino acid metabolism and the control of muscle protein turnover in patients with chronic renal failure. Nutrition, v.15, n.2, p.145-155, 1999.

GREIBER, S., MITCH, W.E. Mechanism for protein catabolism in uremia: metabolic acidosis and activation of proteolytic pathways. Mineral Eletrolyte Metabolism, Basel, v.18, n.2-5, p.233-236, 1992.

JÚNIOR ROMÃO, J.E. Insuficiência Renal crônica. In: CRUZ, J., PRAXEDES, N., CRUZ, H.M.M. Nefrologia. São Paulo : Sarvier, 1994. p.187-200.

LAVILLE, M., FOUQUE, D. Muscular function in Chronic Renal Failure. Advances in Nephology, Chicago, v.24, p.245-263, 1995.

LIM, U.S., YARASHESKI, K.E., FLANIGAN, M.J. The effect of uraemia, acidosis, and dialysis treatment on protein metabolism a longitudinal leucina kinetic study. Nephrology Dialysis Transplant, Berlin, v.13, n.7, p.1723-1730, 1998.

MAY, R.C, MASUD, T., LOGUE, B., BAILEY, J.L., ENGLAND, B.K. Metabolic acidosis accelerates whole body protein degradation and Leucin oxidation by a glucocorticoid-dependent mechanism. Mineral Electrolyte Metabolism, Basel, v.18, n.2-5, p.245-249, 1992.
MITCH, W.E., PRICE, S.R., MAY, R.C., JURKOVITZ, M.D., ENGLAND, M.D. Metabolic consequences of uremia: extending the concept of adaptative responses to protein metabolism. American Journal Kidney Disease, New York, v.23, n.2, p.224-228, 1994.

MITCH, W.E. Metabolic acidosis stimulates protein metabolism in uremia. Mineral Electrolyte Metabolism, Basel, v.22, n.1-3, p.62-65, 1996.

MITCH, W.E., GOLDBERG, A.L. Mechanisms of muscle wasting. New England Journal of Medicine, Boston, v.335, n.25, p.1897-1905, 1996.

MITCH, W.E. Mechanism causing loss of lean body mass in kidney disease. American Journal of Clinical Nutrition, Bethesda, v.67, n.3, p.359-366, 1998.

NARINS, R.G., KRISHINA, G.G., BRESSLER, L. The metabolic acidosis. In: MAXWELL, M.H., KLEEMAN, C.R., NARINS, R.G. Clinical disorders of fluid and electrolyte metabolism. 4.ed. New York: McGraw-Hill, 1987. p.1070-1073.

NEWBY, F.D., PRICE, S.R. Determinants of protein turnover in health and disease. Mineral Electrolyte Metabolism, Basel, v.24, n.1, p.6-12, 1998.

PAPADOYANNAKIS, N.J., STEFANIDIS, C.J., McGEOWN, M. The effect of the correction of metabolic acidosis on nitrogen and potassium balance of patients with chronic renal failure. American Journal of Clinical Nutrition, Bethesda, v.40, n.3, p.623-627, 1984.

PRICE, S.R, BAILEY, J.L., ENGLAND, B.K. Necessary but not sufficient: the role of glucocorticoids in the acidosis-induced increase in levels of mRNA encoding proteins of the ATP-dependent proteolytic pathway in rat muscle. Mineral Electrolyte Metabolism, Basel, v.22, n.1-3, p.72-75, 1996.

REAICH, D., CHANNON, S.M., SCRIMGEOUR, C.M., DALEY, S.E., WILKINSON, R., GOODSHIP, T.H.J. Correction of acidosis in humans with CRF decreases protein degradation and amino acid oxidation. American Journal of Physiology, Bethesda, v.265, n.2, p.230-235, 1993.

WILLIAMS, B., HATTERSLEY, J., LAYWARD, E., WALLS, J. Metabolic acidosis and skeletal muscle adaptation to low protein diets in chronic uremia. Kidney International, New York, v.40, n.4, p.779-786, 1991.

WING, S.S., BANVILLE, D. 14-kDa ubiquitin-conjuating enzime: structure of the rat gene and regulation upon fasting and insulin. American Journal of Physiology, Bethesda, v. 267 (1 pt 1), p.E39-49, 1994.

Recebido para publicação em 14 de outubro de 1999 e aceito em 9 de junho de 2000. 